\title{
The effect of elastic abdominal binder use on respiratory function on persons with high spinal cord injury at orthostatic position.
}

\author{
Efeito da cinta abdominal elástica na função respiratória em pessoas \\ com lesão medular alta na posição ortostática.
}

\author{
Viviane de Souza Pinho Costa', Bianca Teixeira Costa², Rubens Alexandre da Silva Jr'1, Ruy Moreira da Costa Filho³, \\ Jefferson Rosa Cardoso ${ }^{4}$
}

\begin{abstract}
Introduction: Spinal cord injury causes respiratory muscles paralysis, especially in high thoracic paraplegia and tetraplegia with injury above or right on the sixth thoracic segment, and also biomechanics, volumes, capacities and respiratory pressures changes in affected people. The elastic abdominal binder provides a mechanical support for respiratory function treatment, assisting with abdominal restraint and abdominal compliance reduction while at orthostatic position. Objective: To verify the elastic abdominal binder effect on the respiratory function of people with spinal cord injuries during standing position with the help of orthostatic table, from vertical angle position of $60^{\circ}$ and $90^{\circ}$. Method: The study included 56 people suffering from spinal cord injury with motor level above or right on the sixth thoracic segment. They were randomly divided into four distinct groups regarding the use or not of the binder and different inclinations of the orthostatic table during the evaluation procedure. The measured outcomes were vital capacity, tidal volume, inspiratory and expiratory pressure and oxygen saturation. The descriptive analysis presented according to average and standard deviation or median and interquartile. For the outcomes analysis of the five evaluations, the Analysis of Variance (ANOVA) of two factors with repeated measures was used. Statistical significance was set at $5 \%$. Results: The values obtained from respiratory parameters showed no statistical significance regarding the elastic abdominal binder intervention nor on the angle of the standing position. Conclusion: There was no contrasting effect regarding the use of the binder among the evaluated people, therefore it should not be nominated as a standard procedure in the treatment of spinal cord injury at orthostatic position. However, this procedure should not be absolute contraindicated, thus its effect has not demonstrated any harm to participants.
\end{abstract}

Keywords: Tetraplegic, Paraplegic, Respiratory Function, Elastic Abdominal Binder, Physiotherapy.

\section{RESUMO}

Introdução: A lesão da medula espinhal ocasiona paralisia dos músculos respiratórios, principalmente na tetraplegia e paraplegia torácica alta, com lesão acima ou igual ao sexto segmento torácico, e assim mudanças na biomecânica, volumes, capacidades e pressões respiratórias das pessoas acometidas. A cinta abdominal elástica proporciona um suporte mecânico ao tratamento e cuidados com as alterações da função respiratória destas pessoas, podendo auxiliar na contenção abdominal, reduzindo a complacência abdominal durante a posição ortostática. Objetivo: Verificar os efeitos que a cinta abdominal elástica proporciona à função respiratória das pessoas com lesão medular posicionadas em ortostatismo com auxílio da mesa ortostática, a partir da posição a $60^{\circ}$ e $90^{\circ}$ de angulação vertical. Método: Participaram deste estudo 56 pessoas acometidas por lesão medular com nível motor igual ou acima do sexto segmento torácico, divididos aleatoriamente em quatro grupos distintos em relação ao uso ou não da cinta e angulações da mesa ortostática durante o procedimento de avaliação. Os desfechos mensurados foram capacidade vital, volume corrente, pressão inspiratória e expiratória máxima e saturação de oxigênio. A análise descritiva apresentou-se por meio de média e desvio padrão ou mediana e interquartis. Para análise dos desfechos nos cinco momentos avaliados utilizou-se a Análise de Variância (ANOVA) de dois fatores com medidas repetidas. A significância estatística foi estipulada em $5 \%$. Resultados: Os valores encontrados para os parâmetros respiratórios avaliados demonstraram que não houve significância estatística em relação à intervenção cinta abdominal elástica e à angulação do ortostatismo. Conclusão: Não houve efeito diferencial em relação ao uso da cinta nas pessoas avaliadas, não podendo ser indicada como um procedimento padrão para as abordagens de tratamento na posição ortostática na lesão medular espinhal. Em contrapartida, este procedimento não deve ser uma contraindicação absoluta, pois, seu efeito não demonstrou malefícios aos participantes.

Palavras-chave: Tetraplegia, Paraplegia, Função Respiratória, Cinta Abdominal Elástica, Fisioterapia.

Corresponding author: Viviane de Souza Pinho Costa. Center for Health Science Research of Northern Paraná University (UNOPAR), Marselha Street, 591 - Jardim Piza ZIP CODE: 86041-140 - Londrina, Paraná, Brazil. Phone: (43) 3371-9848 / (43) 96491500 - E-mail: vivicosta74@gmail.com

'Physical Therapy Department, Universidade Norte do Paraná (UNOPAR). Master Program in Rehabilitation Sciences Universidade estadual de Londrina (UEL)/UNOPAR. Biological and Health Sciences Center, Universidade Norte do Paraná (UNOPAR), Londrina (PR), Brazil.

Full list of author information is available at the end of the article.

Financial support: National Foundation for the Development of Private Higher Education ( FUNADESP, Brazil)

Submission date 28 September 2015; Acceptance date 08 December 2015; Online publication date 26 December 2015 


\section{INTRODUCTION}

A spinal cord injury $(\mathrm{SCl})$ is one of the most disabling injuries anyone can experience. Personal and social effects are profoundly significant because they confer a lifelong disability on mostly young adults.(1) It causes innervation disruption below the injury due to the loss of the supraspinatus control, and respiratory muscles paralisys, especially in high thoracic paraplegia and tetraplegia, right on or above the sixth thoracic segment, according to the American Society Injury Association (ASIA). ${ }^{(2-4)} \mathrm{SCl}$ has great impact and morbidity and mortality implications, causing respiratory biomechanics, volume, capacity and pressure variations. ${ }^{(1,5-10)}$

The main respiratory complications arising after $\mathrm{SCl}$ are breath shallowness, coughing and sneezing inefficiency, changes in mucociliary clearance and abdominal compliance. These complications can end up as pneumonia, atelectasis and respiratory failures. ${ }^{(6,8,8,10,11)}$

Respiratory tests showed restrictive ventilatory dysfunction in cervical and upper thoracic $\mathrm{SCl}$ patients, as reflected in loss of the chest cavity expansion control and abdominal restraint control $^{(6,12)}$, by motor impairment mainly of the external intercostal muscles (innervation T1 - T12) and abdominal muscles (T6 - T12), according to Gounden ${ }^{(13)}$, Winslow ${ }^{1}$ and Cornwell. ${ }^{(10)}$ All these compose the changes in lung capacity (vital capacity, forced vital capacity and total lung capacity), lung volumes (expiratory reserve and residual volume) and respiratory pressures (maximal inspiratory and expiratory pressures), parameters that are mostly reduced in opposition to the residual volume which tends to increase..$^{(10,12,13)}$

Studies describe that the vital capacity (VC) in with $\mathrm{SCl}$ is reduced at around $30-50 \%$, the functional residual capacity (FRC) is reduced by approximately $25 \%$, and volume of expiratory reserve (VRE) is lowered in $75 \%$ of the standard predicate values indicated by measurement under normal conditions. ${ }^{(5,6,8,13,14)}$ These findings are reflected by the loss of chest and abdominal wall muscles strength control after injury, especially when they are placed in the orthostatic position. In this position abdomen weight is not supported and the postural tone in the abdominal muscles correction does not occur due to abdominal flab, overloading the diaphragm muscle that remains in a lower and flatter position due to gravity, thus restricting and damaging the available diaphragmatic excursion effectiveness due to negative pleural pressure at standing position. ${ }^{(5,8)}$ Studies have reported a decrease of up to $14 \%$ of expected VC for quadriplegics during posture changes, the supine position to sitting or standing. ${ }^{(5)}$

According to Roth, et al. ${ }^{(6)}$, historically, the VC has been used as lung function global measure in its various contexts as well as ventilatory reserve indicator and deep breaths and cough abilities. The maximum inspiratory pressure (MIP) and maximal expiratory pressure (MEP) tests offer, together with the VC, critical information for patient's monitoring and clinical and progressive evaluation, and also to quantify the strength of respiratory muscles and analysis of their actual functions.

In all positions of daily activities taken by people with cervical SCl, values of FRC are lower than the ones measured with not $\mathrm{SCl}$ affected. There has been an increase of these values when changing postures from supine with 20 o slope of the cephalic segment down to the standing position, through various angles $\left(35^{\circ}, 50^{\circ}, 70^{\circ}\right)$ reaching the $90^{\circ}$ angulation. ${ }^{(15)}$

The respiratory parameters changes are results of muscle disorders. The elastic abdominal binder (EAB), cited by some authors $(5,10,12,13,15,16)$, provides a mechanical support during the treatment and care of $\mathrm{SCl}$ respiratory function changes up to to the thoracic middle level. It also assists in abdominal restraint, reducing abdominal compliance during orthostatic position. ${ }^{(16)}$

During the neurofunctional physiotherapy treatment process of $\mathrm{SCl}$ patients, of any level of injury, reestablishing the standing position is a great challenge to face due to the antigravity postural control disorder condition and complications resulting from this impairment. ${ }^{(17)}$

Wadsworth, et al. ${ }^{(8)}$ recently performed a systematic review and meta-analysis covering 11 studies in order to assess the evidence of the EAC use in breathing, speaking and cardiovascular function in $\mathrm{SCl}$ people. The meta-analysis indicated that the EAC use increases VC and reduces the FRC, while on sitting or inclined position, but does not influence significantly the total lung capacity (TLC). However low quality studies were used, resulting in insufficient evidence to support or discourage the use of abdominal binder on patients. Consequently, studies with more rigorous methodological models are needed.

This study aimed to determine the effects EAC provides on the respiratory function of $\mathrm{SCl}$ people while positioned, with the help of an orthostatic table, in different angles $-60^{\circ}$, $90^{\circ}$ of vertical angle.

\section{METHOD}

This is a cross-sectional study with a descriptive and analytical component. ${ }^{(18)}$ Participants were adults affected by $\mathrm{SCl}$. The time of the injury was not delimited. They were classified by Frankel scale modified ASIA, A or B, ${ }^{(19)}$ with injury height at or above T6 (sixth thoracic segment), allowing to perform the orthostatic position during respiratory procedures. Smokers were not excluded. Participants voluntarily agreed to participate in the study by signing the free and informed consent form.

The sample size was defined according to statistical studies, considering the Brazilian Institute of Geography and Statistics data, Census of the year 2000. The sample was determined in 56 participants, randomly divided into four groups for analysis, with two factors: the use or not of the binder and orthostatic table position - orthostatic position at $60^{\circ}$ and 60 and $90^{\circ}$.

This study was approved by the Research Ethics Committee of Regional University Hospital of Northern Parana by 
CEP 009/04, and the TCLE was in accordance with Resolution $466 / 12$ of National Health Council / Brazil.

\section{OUTCOMES ASSESSED}

The VC and minute volume (MV) divided by respiratory rate to obtain tidal volume (TV) were evaluated by means of a hand-held spirometer, the Wright Respirometer, following the recommendations of the American Thoracic Society (1995), with the units of measurement in liters $(\mathrm{L})$ and milliliters $(\mathrm{ml})$, respectively.

The MIP and MEP were assessed by a portable manometer MV-150/300, to measure the inspiratory muscle strength (negative pressure) and expiratory (positive pressure), and its unit measured in $\mathrm{cm} \mathrm{H}_{2} \mathrm{O}$. ${ }^{(13)}$

Oxygen saturation $\left(\mathrm{SpO}_{2}\right)$ was measured by the oximeter portable X model - P-10, easy to use and handling, assisting in obtaining evaluated values, non-invasively with sensor for the fingertip, also supplying the individual heart rate. (20) The measurement unit of pulse oximetry is given as a percentage, and is related to the values in $\mathrm{mmHg}$, arterial gasometry.

\section{PROCEDURES}

Initially all 56 participants had their anthropometric data collected and received training performing breath tests while still sitting in a wheelchair. The best value of three attempts was noted. At the end of this initial phase, an opaque and numbered envelope was randomly opened containing the group characteristics to which the individual would participate. The characteristics were the use or not of EAC and angulation of the standing table $\left(60^{\circ}\right.$ and $\left.60^{\circ} / 90^{\circ}\right)$. The second evaluation phase, which occurred after the initial phase, the participant was placed upright with the help of orthostatic table after vested with or without the use of EAC and using a black opaque vest to hide the EAC intervention.

Manufactured with resistant plastic with Velcro closure, it is composed of $80 \%$ polyester, $15 \%$ elastodiene and $5 \%$ polyamide, containing polypropylene posterior elastic reinforcement. With $20 \mathrm{~cm}$, coming in various sizes (S, M, L and $\mathrm{XL}$ ) for optimal abdominal compression of participants. When used, the setting indication is below the last costal archs and above the upper iliac crests. ${ }^{(9,10)}$ The positioning of EAC was checked before the start of the respiratory tests, in the supine position and in the final moment of the expiratory cycle of each individual, ensuring a more effective abdominal compression.

This study had as research procedure masked type outcomes, carried out by two evaluators, with and without the EAC use in the standing position. Respiratory parameters such as VC, VM, MIP and MEP were collected during the twenty minutes standing posture permanence, being conducted in the first minute and every subsequent five minutes, until total positioning time.
Throughout the procedure, the vital signs and pulse oximetry parameters were collected and monitored for the participants' well-being.

\section{STATISTICAL ANALYSIS}

The descriptive analysis of the sample - age, gender, height, weight, body mass index (BMI), injury height, injury time, etiology and smoking habits - was presented by arithmetic mean and standard deviation, if the assumptions of normality were achieved. For outcomes analysis (VC, average TV, MIP, MEP and $\mathrm{SpO}_{2}$ ) in the first, fifth, tenth, fifteenth and twenty minutes was used Analysis of Variance (ANOVA) of two factors with repeated measures. Statistical significance $(\alpha)$ error type 1 , was set at $5 \%(p<0.05) .{ }^{(21)}$ The statistical program used was SPSS 17.0 (Statistical Package for Social Sciences).

\section{RESULTS}

The work progressed uneventfully for participants; even for those not used to the orthostatic position as a routine in their lives managed to evolve smoothly with breath tests, during the twenty-minute stay in this position. There was only one participant, the group without EAC, who showed postural hypotension in the first ten minutes into testing, claiming vertigo, then returned to starting position and after a brief rest, returned to standing posture accomplishing entire procedure correctly. The participant reported anxiety of getting into a position that hasn't performed in a long time.

The sample consisted of 56 participants, in which 46 (82.1\%) were male and ten (17.9\%) were female. The average age was 35.4 years $(S D=9.8)$, ranging from $18-61$ years. Males reported an average age of 35 years (SD $=9.9$ ) and the female 37.5 years $(S D=9.5)$ and did not show a statistically significant difference. The average height found was 1.72 meters (SD $=0.8$ ) and a weight of $67.1 \mathrm{~kg}(\mathrm{SD}=14.6)$. The mean BMI was $22.3 \mathrm{~kg} / \mathrm{m}^{2}$ $(S D=3.9)$, the average male of $22.6 \mathrm{~kg} / \mathrm{m}^{2}(\mathrm{SD}=4)$ and females $21.1 \mathrm{~kg} / \mathrm{m}^{2}$ (SD = 3.7).

The height of the $\mathrm{SCl}$ ranged from $\mathrm{C5}$ (fifth cervical neurological segment) through T6. The highest frequency was at the level of T4 (fourth thoracic segment), with ten cases (17.9\%). As for the etiology, the car accident represented the greater frequency of sample with 22 cases (39.3\%). According to the classification established by ASIA, most participants are framed as ASIA A ( $n=43 ; 76.8 \%)$. The time since injury ( $\mathrm{SCI}$ ) was represented by the median ( $1^{\text {st }}$ and $3^{\text {rd }}$ quartiles) at 96 onths (51 and 168), and the men had a median of 132 months (84 and 180), and the female 84 months (48 and 156).

The analytical results of clinical outcomes are related to respiratory tests in the participants in the standing position in five different moments of implementation $\left(1^{\text {st }}, 5^{\text {th }}, 10^{\text {th }}, 15^{\text {th }}\right.$ and $20^{\text {th }}$ minutes) and with different angles (the only $60^{\circ}$ and over $60^{\circ}$ and $90^{\circ}$ ). All these results were from two-factor ANOVA with repeated measurements. 
The VC presented the highest average of this study in the first three moments $\left(1^{\text {st }}, 5^{\text {th }}\right.$ and $10^{\text {th }}$ minutes) in the group regarding the use of EAC to $60^{\circ}$ and $90^{\circ}$. And also the highest peak after 15 minutes in the group with the binder at only $60^{\circ}$. (Figure 1 )

The TV analyzed had the highest values with the group that used the binder to $60^{\circ}$ and $90^{\circ}$ in all evaluated moments. (Figure 2)
In the evaluation of MIP, the most evident averages were obtained in the group using the binder at only $60^{\circ}$ at all times. (Figure 3)

For MEP, the highest averages recur within the group that uses the binder in angles of $60^{\circ}$ and $90^{\circ}$ in the first three moments and declining in the $15^{\text {th }}$ minute, in relation to the other groups, and subsequent rise in the $20^{\text {th }}$ minute of the same group. (Figure 4)

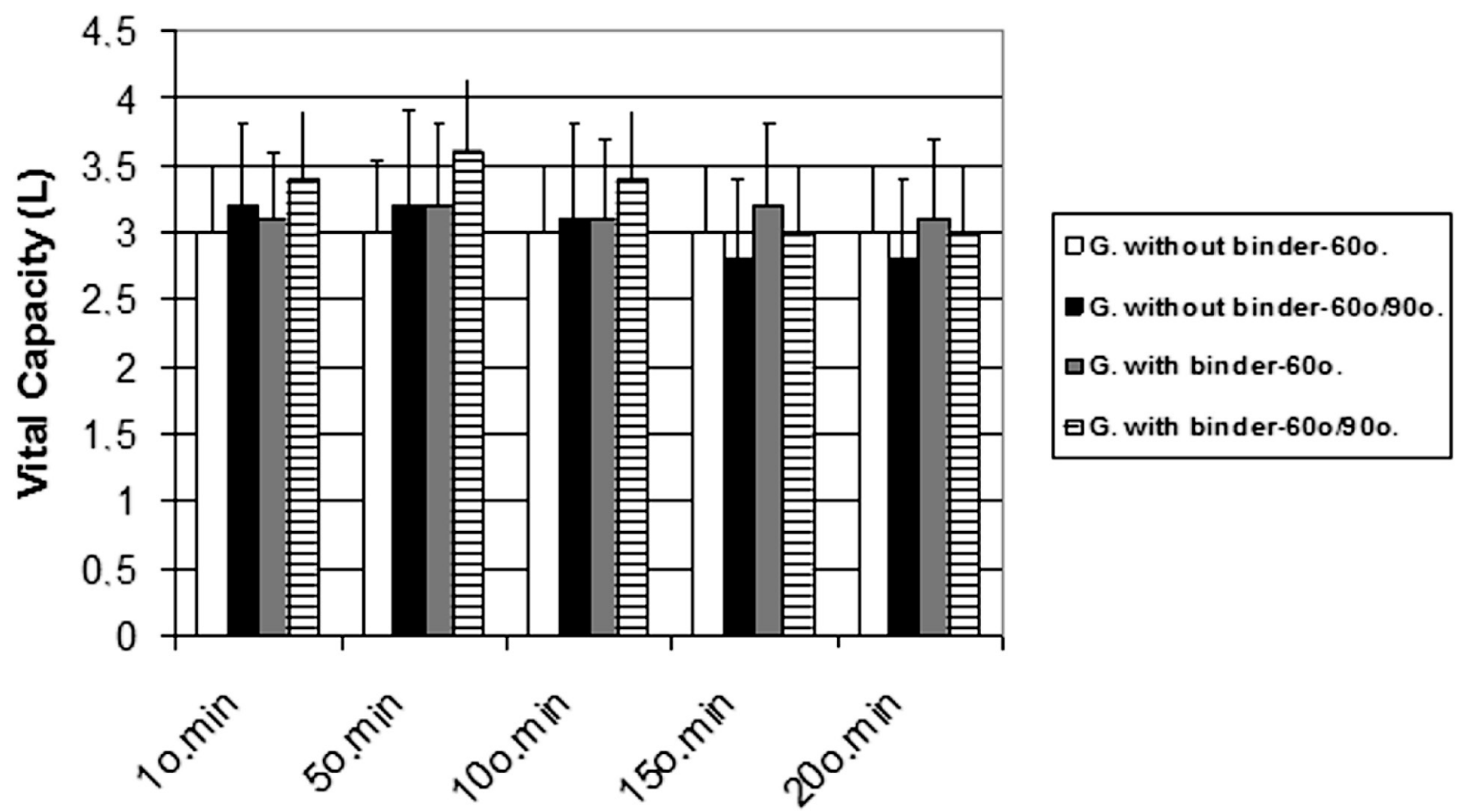

Figure 1. Arithmetic means obtained from the VC when compared among the four groups in five different moments.

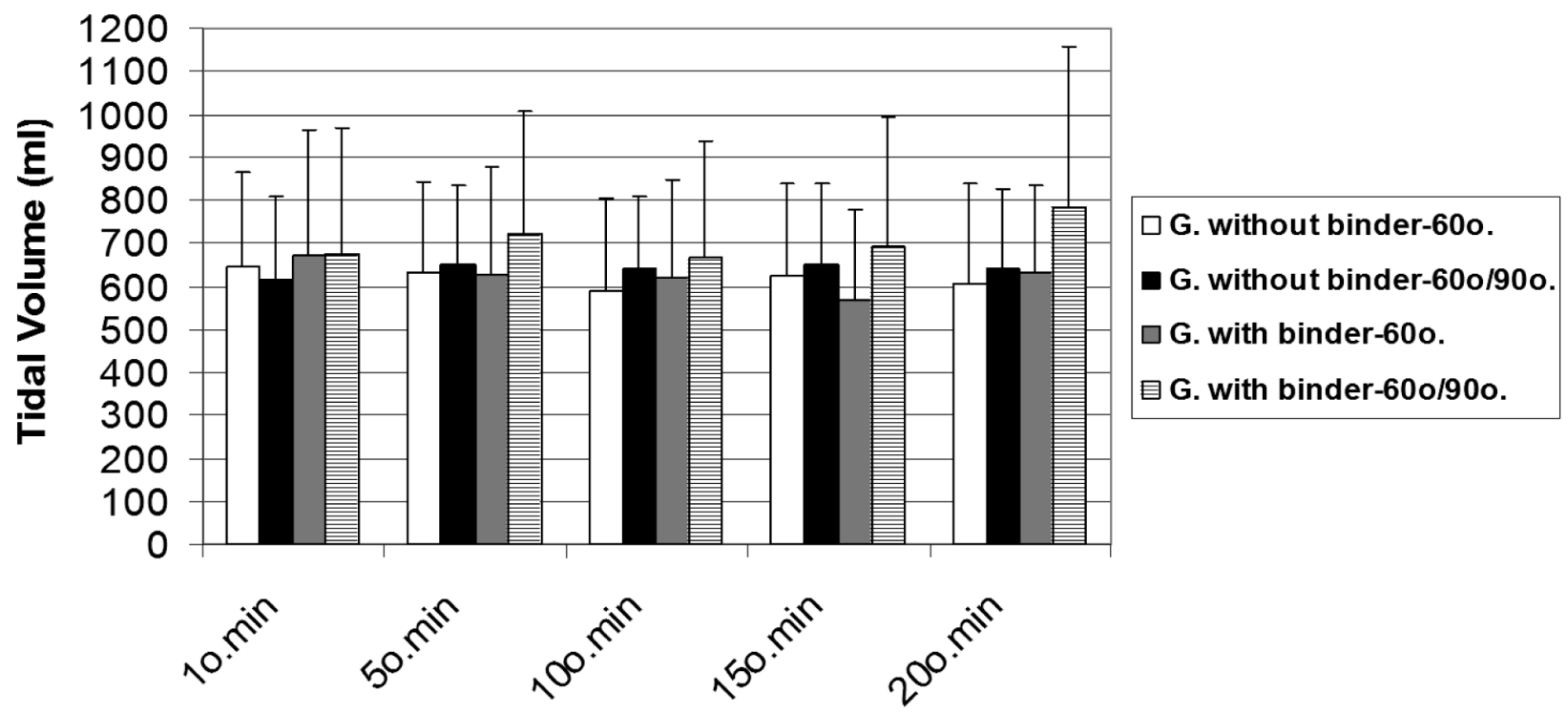

Figure 2. Arithmetic means obtained from the TV when compared among the four groups in five different moments. 


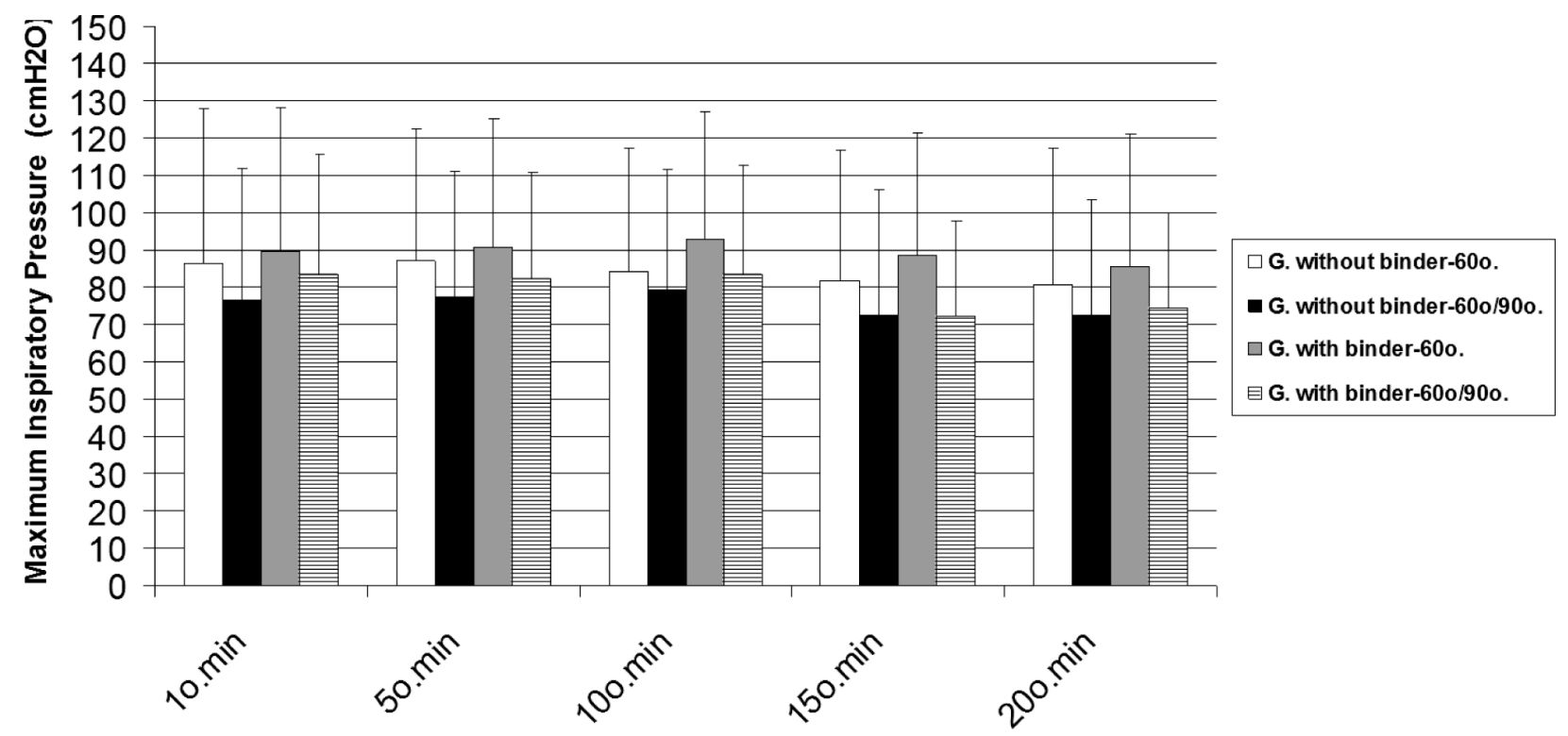

Figure 3. Arithmetic means obtained from MIP when compared among the four groups, in five different moments.

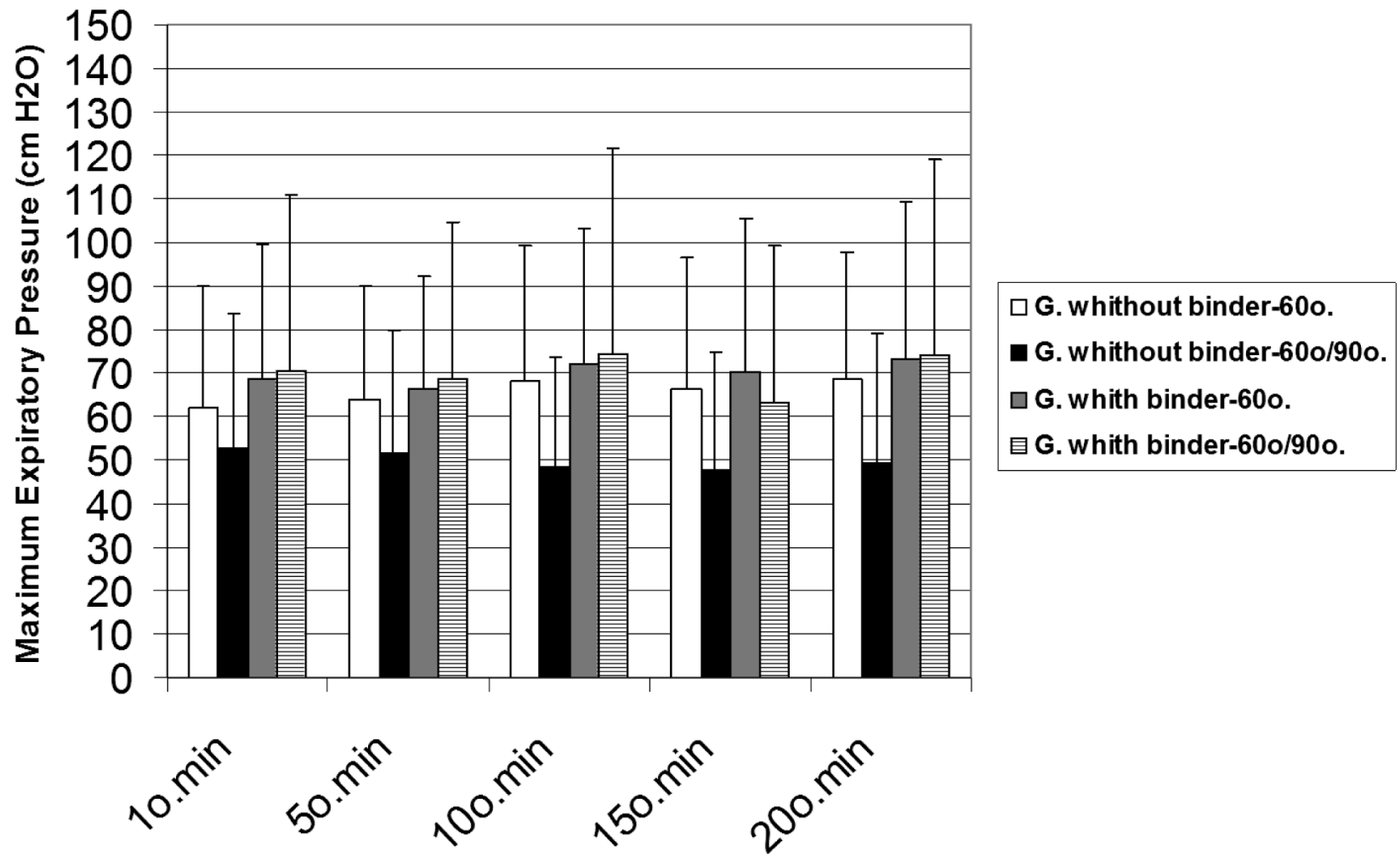

Figure 4. Arithmetic means obtained from MEP when compared among the four groups, in five different moments.

And $\mathrm{SpO} 2$ showed its worst values in the group with the binder at $60^{\circ}$ and $90^{\circ}$, as mentioned in the previous outcomes, being their best average on $1^{\text {st }}$ and $20^{\text {th }}$ minutes of the group using the binder at only $60^{\circ}$. (Figure 5 )

\section{DISCUSSION}

The most common age of impairment includes the average age of 31.7 years, and at 19, the most affected age, the prevalence according to gender shows up in males, occurring 


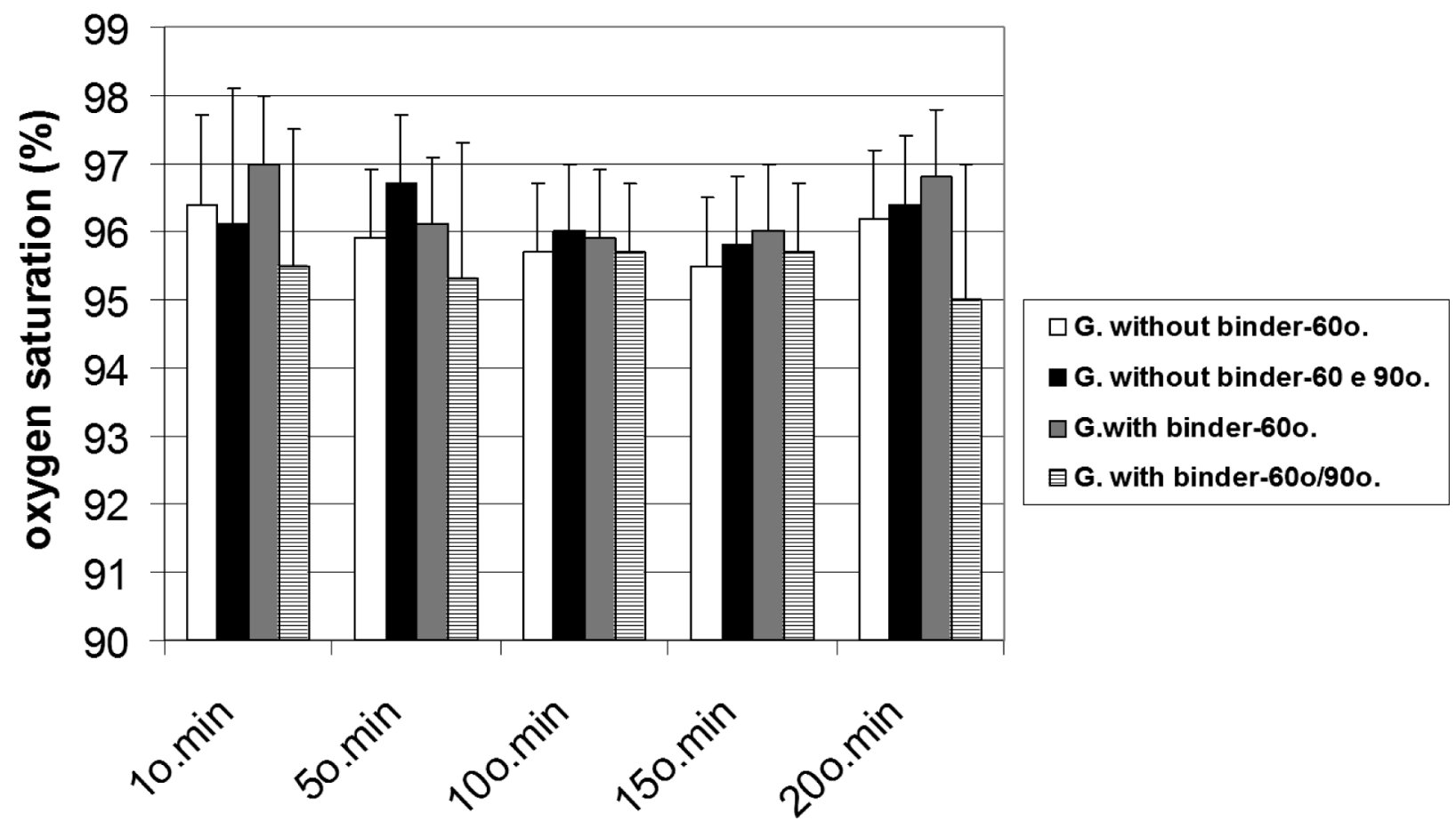

Figure 5. Means of $\mathrm{SpO}_{2}$ when compared among the four groups, in five different moments.

in $81.8 \%$ of cases of $\mathrm{SCl}$, being its main cause, accidents with motor vehicles, figures presented in the United States. ${ }^{(22)}$ This study portrayed a sample of participants with an average age of 35.4 years $( \pm 9.8)$. The predominant gender, as already described, agreeing with worldwide data, was the males with 46 participants (82.1\%). The most common etiologies were automobile and motorcycle accidents with 22 (39.3\%) and 14 cases (25\%), respectively. Classification for neurological category was 38 evaluated people with paraplegia (67.9\%) fitting as ASIA A in 43 cases (76.8\%), and the level of the injury in T4 (fourth thoracic neurological segment) with 10 cases (17.9\%).

The use of EAC has been a subject studied by several authors such as Boaventura et al. ${ }^{(12)}$, Estenne and De Troyer ${ }^{(14)}$, Goldman et al. ${ }^{(16)}$, Bodin et al. ${ }^{(23)}$ and Cornwell et al. ${ }^{(10)}$ and these studies have demonstrated its effect on the various changes in respiratory function in people suffering from high $\mathrm{SCl}$ in different situations to those presented in this paper. The correlation between the standing position and the various angles $\left(60^{\circ}\right.$ and $\left.60^{\circ} / 90^{\circ}\right)$ performed in these procedures have not been described previously.

Eng et al. ${ }^{(24)}$ produced a very thorough data collection with the application of a research instrument containing 17 items to be answered at home for people with $\mathrm{SCl}$, making a total of 153 participants. It listed twelve situations of benefits earned with prolonged use of standing posture, and respondents were able to correlate the benefits and adverse effects on each of the twelve items. The answers showed first item of physical well-being, where just a few negative aspects were mentioned, and then in sixth place described breathing, presented with many negative aspects. Aspects related to neurological deficits caused in muscles after $\mathrm{SCl}$.

In quadriplegia, provided the paralysis of the abdominal muscles due to $\mathrm{SCl}$, the great dorsal muscle, teres major, and the clavicular portion of the greater pectoral trigger to make such effort as respiratory cough. ${ }^{(1,25)}$ Fujiwara et al, ${ }^{(25)}$ then reports as a completion of their studies the importance of these accessory muscles great dorsal innervated by C6 - C 8 and clavicular portion of the greater pectoral with innervation of C5 - C7, which are muscles that in not $\mathrm{SCl}$ compromised act as accessories in inspiration. It suggests that there is an increase in intrathoracic pressure at the time of expiratory effort for quadriplegic people, that have them partially innervated, and yet, with better muscle performances the lower the height of spinal cord injury.

Winslow $^{(1)}$, Pryor and Webber ${ }^{(26)}$, reinforce that the higher the level of the $\mathrm{SCl}$, the greater the functional consequence for breathing. People with thoracic injuries have some preservation of intercostal function but paralysis of the abdominal muscles. Therefore, the lower the height of the injury, the more it approaches inspiratory capacity of normal values, although paralysis of the abdominal muscles result in a decrease in the potential expiratory effort. These findings suggest the importance of the approach and care of respiratory function in people with quadriplegia, and may consider a study 
involving a larger number of participants in these conditions, would result in more meaningful values for the use of EAC.

Differences between engaged or not by the $\mathrm{SCl}$ may be assigned to the abdominal tone change, which in normal people spontaneously occurs increasing muscle tone when they stand, promoting waist restraint and proper intra-abdominal pressure is maintained, allowing the diaphragm to make a normal excursion in its movement. ${ }^{(1,16,23)}$

In case of paralysis of the abdominal wall, the person may need bandages or EAC to assist abdominal restraint and maintain the relationship of normal pressure in various postures adopted, as in the standing position. . $^{(5,16,23,27)}$

The $\mathrm{CV}$ related to the orthostatic position, although there was no statistical significance $(p>0.05)$ between the EAC interference, remained with most constant average values throughout the procedure with the use of EAC. There were more obvious changes from the $15^{\text {th }}$ minute with declines in average values by changing the angle of the table, especially in the group that did not use the binder.

Therefore, based on this study, despite the EAC use effect not to be significant, it also does not interfere with CV, so when the individual feels comfortable, safe, better positioned and has an overall wellness feeling in the orthostatic table, it can be indicated because when asked verbally without written data being collected, after the completion of the procedures on the use of EAC, all participants who have used it have reported favorable responses, with no discomfort and breathing difficulties due to compression, and without hurting them. Also reported the security of the body when put in standing position for the restraint provided by it, and some already use EAC for this procedure. These qualitative data were not yet described in the literature.

Other studies such as Estenne et al. ${ }^{(28)}$, compare the evaluation of respiratory parameters with eight people with quadriplegia sitting in their wheelchairs, performing an abdominal bandage with non-elastic straps intended to promote containment of the abdominal content, replacing the paralyzed muscles. The findings showed significant increase in $\mathrm{CV}$, as similar to those already mentioned in other studies such as Bodin et al. ${ }^{(23)}$, who observed in 20 participants with spinal cord injury. Boaventura et al. ${ }^{(12)}$ also assessed 10 people with quadriplegia seated and supine position, with and without the use of EAC for abdominal restraint, as in the aforementioned study, and the results also confer increased CV.

The TV tends to decrease its values in accordance with the reduction of the transdiaphragmatic pressure in quadriplegia and high paraplegia when compared to the supine position, a result also related to paralysis of the abdominal muscles and reduced muscle tone for proper abdominal restraint, not permitting abdominal pressure to increase and keeping the zone of apposition low. Winslow ${ }^{1}$ justifies this condition, but describes that there is a $16 \%$ increase in TV in addition to the use of EAC as it improves the excursion of the rib cage in the anteroposterior and lateral diameters during inspiration in these.
This study showed no statistical improvement of TV in the groups that used the EAC, by keeping its average values constant, distinguishing only the group that used the EAC and carried out the postural change to $90^{\circ}$, and had higher values during the whole procedure, with the highest peak in the last rated minute ( $X=783 \mathrm{ml} \mathrm{TV}$ ). In contrast, the MIP at the same time decreased $\left(X=-74 \mathrm{~cm} \mathrm{H}_{2} \mathrm{O}\right)$ compared to the other averages of this parameter.

The related fact may have occurred due to muscle fatigue of preserved muscles, ie, accessory musculature involved in inspiration and preserved intercostal muscles in people with high paraplegia, generating decrease in MIP by inefficiency in muscle strength, even with the use of EAC. In contrast, the best performance while maintaining the highest average MIP was the group that used the EAC only in the $60^{\circ}$ angle.

Goldman et al. ${ }^{(16)}$, also mentions in his studies MIP data that were not significant in the standing posture at $70^{\circ}$, and participants reported on their research difficulties in performing the tests due to the great effort that the test requires and also felt a falling sensation during this procedure.

Wadsworth et al. ${ }^{(9)}$ investigated the effect of the use of EAC on lung function in 14 people with complete quadriplegia during the first year after the $\mathrm{SCl}$, evaluated after 6 weeks, 3 months and 6 months of the start of the daily use of EAC, while in the wheelchair, in a sitting position. Statistically significant values were found for MIP ( $p=0.01)$, but there was no statistically significant improvement in MEP ( $p=0.11)$.

The MEP promotes relevant information regarding the individual's ability to cough. High expiratory pressures are required during the expulsive phase of the cough reflex to cause a dynamic compression in the air ways. People with high $\mathrm{SCl}$ and paralysis of the expiratory muscles have this mechanism altered and consequent inefficiency of coughing and must be monitored constantly as their MEP, as cites Gounden ${ }^{(13)}$ on their reports, as prophylactic measures to prevent complications such as pulmonary infections. It cites further that as the MEP is volume-dependent, thus reducing the values of this parameter, there should be a reduction in CV.

Cornwell et al. ${ }^{(10)}$ evaluated, seated with and without the use of EAC, 13 people with complete $\mathrm{SCl}$, between $\mathrm{C} 3$ and $\mathrm{T} 1$, after using EAC for 6 consecutive weeks, noting a significant increase in $\mathrm{CV}$ in $13 \%$ and $15 \%$ in MEP.

Regarding the parameters evaluated by $\mathrm{SpO}_{2}$ as a way to monitor the participants during all procedures also showed no statistically significant differences compared to the use or not of EAC. What has been observed is that the average values were normal and constant for the analyzed parameter, showing that participants remained with the conditions related to perfusion / ventilation and respiratory volumes favorable, also providing heart rates for monitoring during the development of study ${ }^{(21)}$.

As limitations and implications observed in this study, we can mention the heterogeneous selection of participants in relation to the topographies of motor and sensory levels of 
the $\mathrm{SCl}$ and the time of its commitment to detect probable statistical differences for the analyzed parameters. The use of spirometer as an evaluation tool in this study was not possible because its use is necessary for a long period of time and in various locations in different cities and Private Clinic Schools, the high sensitivity of the equipment and high maintenance costs, as well as complexity and requirements of the tests to be conducted in short periods of time throughout the orthostatic procedure.

Therefore, it is suggested to conduct further research focusing on other outcomes and assessment parameters of respiratory function and cardiovascular parameters related to the use of EAC and between groups of people only with quadriplegia or high paraplegia. And the appointment of qualitative studies addressing the relation of the person's sensation with spinal cord injury on the use of EAC in the various procedures adopted in these people's physical therapy treatments and daily activities.

\section{CONCLUSION}

The study used the procedure with and without the use of EAC with the participants in a standing position in the orthostatic table, such aspect so little analyzed and described in other studies that discuss the same topic. And the study sample consisted of 56 participants, among which 38 were people with neurological classification of high thoracic paraplegia and 18 with quadriplegia, elucidating a change assessment work in $\mathrm{SCl}$ respiratory function, with a large number of paraplegics, which is little explored by other authors, who generally evaluate quadriplegic.

The numerical findings statistically analyzed showed no differential effect regarding the use of EAC in the evaluated participants and must not be indicated as a standard procedure for treatment approaches in the standing position in $\mathrm{SCl}$. In contrast, this statement should not be an absolute contraindication, because its effect has not demonstrated any harm to study participants.

\section{ACKNOWLEDGEMENTS}

Special thanks to my supervisor Marcia Regina Antonietto Costa Melo, for her care, patience, respect and maternal friendship, especially for her contribution to my learning.

\section{AUTHOR'S CONTRIBUTIONS}

All authors participated in data collection, analysis and writing of the manuscript.

\section{FINANCIAL COMPETING INTERESTS}

The authors declare no conflicts of interest in this work.

\section{AUTHOR DETAILS}

${ }^{2}$ Master Program in Rehabilitation Sciences Universidade estadual de Londrina (UEL)/UNOPAR. Biological and Health Sciences Center, Universidade Norte do Paraná (UNOPAR), Londrina (PR), Brazil; 3 Physical Therapy Department, Universidade estadual de Londrina (UEL), Londrina (PR), Brazil; 4 Physical Therapy Department, Universidade estadual de Londrina, Londrina (PR), Brazil. Master Program in Physical Education UEL Universidade estadual de Maringá (UEM), Londrina (PR), Brazil.

\section{REFERENCES}

1. Winslow C, Rozovsky J. Effect of spinal cord injury on the respiratory system. Am J Phys Med Rehabil. 2003;82:803-814.

2. Schneider FJ. Lesão Medular Traumática. In: Umphred DA (Editor). Fisioterapia Neurológica. 2ed. São Paulo: Manole; 1994. p 421-481.

3. Maynard FM Jr, Bracken MB, Creasey G, Ditunno JF Jr, Donavan WH, Ducker TB, et al. Internacional standarts for neurological and functional classification of spinal cord injury. Spinal Cord. 1997;35:266-274.

4. Andrada L, Vito EL. Evaluacion funcional respiratoria en pacientes con lesion medular traumatica alta. Medicina. 2001;61:529-534.

5. Chen CF, Lien IN, Wu MC. Respiratory function in patients with spinal cord injuries: effects of posture. Paraplegia. 1990;28:81-86.

6. Roth EJ, Nuussbaum SB, Berkowitz M, Primack S, Oken J, Powley S, et al. Pulmonary function testing in spinal cord injury: correlation with vital capacity. Paraplegia. 1995;33:454-457.

7. Roth EJ, Lu A, Primack S, Oken J, Nuusbaum S, Berkowitz M, et al. Ventilatory function in cervical and high thoracic spinal cord injury: relationship to level of injury and tone. Am J Phys Med Rehabil. 1997;76:262-267.

8. Wadsworth BM, Haines TP, Cornwell PL, Paratz JD. Abdominal binder use in people with spinal cord injuries: a systematic review and meta-analysis. Spinal Cord. 2009;47:274-285.

9. Wadsworth BM, Haines TP, Cornwell PL, Rodwell LT, Paratz JD. Abdominal binder improves lung volumes and voice in people with tetraplegic spinal cord injury. Arch Phys Med Rehabil. 2012;93:2189-2197.

10. Cornwell PL, Ward EC, Lim Y, Wadsworth, B. Impact of an Abdominal Binder on Speech Outcomes in People With Tetraplegic Spinal Cord Injury: Perceptual and Acoustic Measures. Top Spinal Cord Inj Rehabil. 2014;20:48-57.

11. Wang AY, Jaeger RJ, Yarkony GM, Turba RM. Cough in spinal cord injuried patients: the relationship between motor level and peak expiratory flow. Spinal Cord. 1997;35:299-302.

12. Boaventura CM, Gastaldi AC, Silveira JM, Santos PR, Guimarães RC, Lima LC. Effect of abdominal binder on the efficacy of respiratory muscle in seated and supine tetraplegic patients. Physiotherapy. 2003;89:290-295.

13. Gounden P. Static respiratory in patients with post-traumatic tetraplegia. Spinal Cord. 1997;35:43-47.

14. Estenne M, De Troyer A. Mechanism of the postural dependence of vital capacity in tetraplegics subjects. Am Rev Respir Dis. 1987;135:367-371.

15. Ali J, Qi W. Pulmonary function and posture in traumatic quadriplegia. J Trauma. 1995;39:334-337.

16. Goldman JM, Rose LS, Williams SJ, Silver JR, Denison DM. Effect of abdominal binders on breathing in tetraplegic patients. Thorax. 1986;41:940-945.

17. Kunkel CF, Scremin AM, Eisenberg B, Garcia JF, Roberts S, Martinez S. Effect of "Standing" on Spasticity, Contracture, and Osteoporosis in Paralyzed Males. Arch Phys Med Rehabil. 1993;74:73-78.

18. Medronho RA. Epidemiologia. São Paulo: Atheneu; 2003.

19. Defino HLA. Trauma raquimedular. Medicina. 1999; 32: 388-400.

20. Pacheco AM, Amim RST. Desmame da ventilação mecânica. Fisioterapia Brasil. 2003;4:295-299.

21. Rosner B. Fundamentals of Biostatistics. 5 ed. Pacific Grove: DuxburyThomson Learning; 2000.

22. Atrice MB, Morrison SA, McDowell SL, Shandalov B. Lesão Medular Traumática. In: Umphred DA (Editor). Reabilitação Neurológica. 4 ed. São Paulo: Manole; 2004. p.506-560. 
23. Bodin P, Fagevik Olsén M, Kreuter M. Effects of abdominal binding on breathing patterns during breathing exercises in person with tetraplegia. Spinal Cord. 2005;43:117-122.

24. Eng JJ, Levins SM, Townson AF, Mah-Jones D, Bremner J, Huston G. Use of Prolonged Standing for With Spinal Cord Injuries. Phys Ther. 2001;81:1392-1399.

25. Fujiwara T, Hara Y, Chino N. Expiratory function in complete tetraplegics: study of spirometry, maximal expiratory pressure, and muscle activity of pectoralis major and latissimus dorsi muscles. Am J Phys Med Rehabil. 1999;78:464-469.
26. Pryor JA, Webber BA. Fisioterapia para Problemas Respiratórios e Cardíacos. 2 ed. Rio de Janeiro: Guanabara Koogan; 2002.

27. Mccool FD, Pichurko BM, Slustsky AS, Sarkarati M, Rossier A, Brown R. Changes in the volume and rib cage configuration with abdominal binding in quadriplegia. J Appl Physiol. 1986;60:1198-1202.

28. Estenne M, Van Muylem A, Gorini M, Kinnear W, Heilporn A, De Troyer A. Effects of abdominal strapping on forced expiration in tetraplegic patients. Am J Respir Crit Care Med. 1998;157:95-98.' 